\title{
Market Pricing of Fundamentals at the Shanghai Stock Exchange: Evidence from a Dividend Discount Model with Adaptive Expectations
}

\author{
Mingyang Li, Linlin Niu ${ }^{\dagger}$ Andrew Adrian Pua
}

Dec 30, 2020

\begin{abstract}
We study market pricing of fundamentals at the Shanghai Stock Exchange, incorporating possible irrational pricing behavior with adaptive expectation. Using panel data of listed stocks to overcome the limited information in aggregate time series data, we estimated key parameters of the price elasticity of dividends and the expectation adjustment based on a linear dynamic panel data model. We use a major subset of stocks with stationary real prices and cash flows and apply methods that correct for incidental parameter bias. The resulting price elasticity of dividends is about 0.46 (0.35) based on annual (quarterly) data, which is sizable given high $\mathrm{PD}(\mathrm{PE})$ ratios in the market. Our results imply that slow expectation adjustment contributes to "bubble-like" price patterns. We also show prices significantly react to macro information related to the discount rate, but these effects are very sensitive to the information set used.
\end{abstract}

Keywords: Stock price determination, Adaptive expectation, Time-varying discount rate, Incidental parameter bias

JEL code: G12, C33, C58

\footnotetext{
*Wang Yanan Institute for Studies in Economics, Xiamen University, China

${ }^{\dagger}$ Gregory Chow Center for Economic Research and Wang Yanan Institute for Studies in Economics, Xiamen University, China

${ }^{\ddagger}$ School of Economics and Wang Yanan Institute for Studies in Economics, Xiamen University, China

${ }^{\S}$ We thank Gregory Chow for valuable discussion, thank seminar participants at Xiamen University and Humboldt University of Berlin for useful comments. We acknowledge the support of the NSFC Grants (Nos. 71528008 and 71273007) and the Deutsche Forschungsgemeinschaft, Germany through the SFB 649 "Economic Risk".
} 


\section{Introduction}

Like many stock markets in emerging economies with short history and large body of unsophisticated investors, China's stock market is known to be volatile and speculative. As China became the world's second-largest economy and a global economic engine, its stock market performance and capability of fundamental pricing are of increasing importance to domestic and foreign investors. By fundamental, we mean expected cash flows in dividends or earnings and discount rate in a classical present value framework, which can be driven by macroeconomic conditions. Although irrational pricing behaviors have been frequently documented in this market (Mei, Scheinkman, \& Xiong, 2009; Xiong \& Yu, 2011; Choi, Jin, \& Yan, 2012; Kong, Lin, \& Liu, 2017), there are also studies supporting price informativeness on fundamentals using cross-sectional data based on indirect evidence on returns or earnings predictability, and explaining portfolio excess returns by factors relating to firm characteristics (Carpenter, Lu, \& Whitelaw, 2018; Liu, Stambaugh, \& Yuan, 2019). Yet, it is a largely unanswered question on how the (log) real stock prices react to fundamentals at the market level, which is not only essential to the payoff of investors employing indexation strategy, but also central to academia and policy makers to assess the efficacy and efficiency of the stock market functions.

In particular, stock prices in emerging markets exhibit higher synchronicity than those in developed economies due to various institutional characteristics, which is also evident in China (Morck, Yeung, \& Yu, 2000; Gul, Kim, \& Qiu, 2010; Hasan, Song, \& Wachtel, 2014). Higher degree of price co-movements implies that studying market pricing is key to understanding driving factors behind individual stock pricing. Our paper aims to tackle this important issue on the market pricing mechanism in China by directly measuring price reaction to fundamentals.

To start with, the challenges of limited data at the aggregate level and possible nonstationarity need to be addressed. As far as aggregate time series data are concerned, the 
cash flow data of dividends or earnings as fundamental information has limited sample due to a low frequency of annual or quarterly disclosure with a merely less than thirty years' history of the market. To overcome the relatively short span of aggregated stock market information, we turned to firm level data and used two datasets - a yearly unbalanced panel of 729 stocks from 1997 to 2018 and another quarterly unbalanced panel of 854 stocks from 2007Q1 to 2019Q2. However, nonstationarity may appear due to speculative pricing behavior or fast-growing sectors with underlying trends in the short run, which turned the literature from "asset pricing" to "asset expected returning" (Cochrane, 2011; Favero, Melone, \& Tamoni, 2020). Using a suggested procedure in Ng (2008) and further modified by Westerlund (2016), we trimmed away the fraction of stocks in the cross-section which could potentially affect the estimated dynamics of the panel due to nonstationarities. In contrast, the nonstationarities considered in a similar empirical application by Bhargava (2014) are much less general than what was considered in Ng (2008) and Westerlund (2016). It turns out that the selected stationary series account for a major proportion of stocks both in numbers and market values in the two samples used. This finding is also in line with evidence of persistent but transitory components in both the common and idiosyncratic price components in the US market (Poterba \& Summers, 1988; Cohen, Polk, \& Vuolteenaho, 2009; Bhargava, 2014).

Following Chow (1989), we derive the linear relationship between log price and fundamental variables as an approximation to the present value model under the assumption of adaptive expectation. As shown in Chow (1989), either under adaptive expectation or rational expectation, the resulting reduced-form model is observationally equivalent, but the structural model with adaptive expectation can better accommodate speculative pricing behaviors evidenced in the literature and the inference on the structural parameter of adaptive adjustment helps to explain the mechanism of persistent price pattern and deviation from equilibrium levels. 
Methodologically, we need to apply bias correction to properly quantify the fundamental pricing effects. For the reduced-form model, by using the split-panel jackknife (Dhaene \& Jochmans, 2015), we show that correction can be made to the downward bias of price reaction induced by the presence of incidental parameters. The incidental parameter bias is sizable, especially given the size of the panel datasets we used. More importantly, we find that the downward bias related to the structural parameter of adaptive expectation adjustment is even more substantial. Although many corrections and approaches were proposed in the literature as surveyed by Fernández-Val and Weidner (2018) in detail, empirical applications of these corrections have been extremely limited. Our work presents a useful application to illustrate the importance of correcting such bias in economics and finance research.

Besides our benchmark specification including firm and time fixed effects, we also consider a specification that excludes time fixed effects but includes observable determinants of the time-varying discount factor common to all firms. Although early work with aggregate data gave little evidence on the importance of the time-varying discount rate (Campbell \& Shiller, 1988), it has been recognized in the recent asset pricing literature that the discount rate variation is crucial to asset pricing (Cochrane, 2007, 2011). Furthermore, asset pricing relies on the stochastic discount factor, which is driven by consumption smoothing, risk sharing and dynamic general equilibrium (Cochrane, 2005). As a result, we can determine the relative importance of these observable determinants in generating price movements on top of the information on cash flows of the firm.

The rest of the paper is organized as follows: Section 2 introduces the structural model of stock price determination with adaptive expectations. Section 3 describes the data and variable construction. Section 4 conducts empirical analysis, including presenting the estimation strategy, documenting a small simulation study to show the importance of correcting the incidental parameter biases of the reduced form parameters, and presenting 
the main estimation results. Section 5 concludes.

\section{A dividend discount model with adaptive expecta- tions}

We first lay out the log-linearized discounted dividend model (DDM) with adaptive expectation (Chow, 1989) and discuss its relationship with a reduced form estimable using panel data. In this framework of stock price determination, there are two notions of a fundamental: a firm-specific fundamental of cash flow information on dividends or earnings and a macroeconomic fundamental driving the time-varying discount rate, as described by consumption-based pricing framework (Cochrane, 2005). We study the price determinants in real terms, so that all nominal variables are adjusted for inflation.

\section{$2.1 \quad$ Theoretical model}

The DDM serves as a benchmark model for stock price determination. By definition, the total return of buying stocks incorporates capital gain and dividend payoff:

$$
1+R_{t+1}=\left(P_{t+1}+D_{t}\right) / P_{t}
$$

where $P_{t}$ is the stock price at the beginning of period $t$, and $D_{t}$ is the dividend paid during period $t$. Let $E_{t}(\cdot)$ be an expectation operator with information set up to time t. Assuming constant expected rate of return, for simplicity, $E_{t} R_{t+1}=R$, and taking expectations on both sides of (1) leads to:

$$
P_{t}(1+R)=E_{t}\left(P_{t+1}+D_{t}\right)
$$


Following Gordon (1962), assuming a constant growth rate of dividend, $D_{t+s}=(1+g)^{s} D_{t}$, thus:

$$
P_{t}=\sum_{s=1}^{\infty} E_{t} D_{t}(1+g)^{s} /(1+R)^{s+1}=\left(E_{t} D_{t}\right) /(R-g)
$$

Taking logs on both sides, one has:

$$
p_{t}=\log P_{t} \approx \log E_{t} D_{t}-\log (R-g)
$$

(3) states that the log of stock price is a linear function of the expected dividend and the difference between the dividend growth rate and discount rate. Note that dividends are firm-specific cash flow information, while the discount rate typically move with macroeconomic conditions. Other things being equal, (2) and (3) imply that firms paying more dividends should be priced higher.

In our empirical study, we are concerned about whether and to what extent dividends are priced. That is, we are interested in the coefficient in an equation such as

$$
p_{t}=\gamma^{*}+\delta \log E_{t} D_{t}
$$

where $p_{t}$ denotes the theoretical part of price determined by the DDM expected component, and $\delta$ measures the price elasticity of dividend.

Since the expected dividend is unobserved, we are not able to estimate (4) directly. Therefore, assumptions about expectation formation are needed at this stage. To conduct inference on $\delta$, we follow Chow (1989) and assume a form of adaptive expectation formation. That is, the log of expected dividend is based on the log of lagged expectation $E_{t-1} D_{t-1}$, adjusted by the difference of the log of the most recently available dividend 
information $D_{t-1}$ and the log of lagged expectation. In particular, we have

$$
\begin{aligned}
E_{t} D_{t} & =\left(D_{t-1}\right)^{c}\left(E_{t-1} D_{t-1}\right)^{1-c} \\
\log E_{t} D_{t} & =c \log D_{t-1}+(1-c) \log E_{t-1} D_{t-1} \\
\log E_{t} D_{t} & =c[1-(1-c) L]^{-1} \log D_{t-1},
\end{aligned}
$$

where $0 \leq c \leq 1$ is the adjustment parameter. Note that $(1-c)$ measures the learning inertia. The closer $c$ is to 1 , the quicker is the adaptation towards rational expectations. With the lag operator $L$, the current expectation $E_{t} D_{t}$ can be expressed as a function of the lags of past realized dividends. By multiplying $c[1-(1-c) L]^{-1}$ on both sides of (4), the price determination can be transformed to

$$
p_{t}=\gamma+\beta_{1} p_{t-1}+\beta_{2} d_{t-1}
$$

where $d_{t-1}=\log D_{t-1}, \gamma=\gamma^{*} c, \beta_{1}=1-c$, and $\beta_{2}=c \delta$. As a result, we can estimate the parameters $\beta_{1}$ and $\beta_{2}$ in the reduced form (8) and then recover the structural parameters representing the price elasticity of dividends $\delta$ in (4) and the speed of adjustment $c$ in (7). In fact, $\delta=\beta_{2} /\left(1-\beta_{1}\right)$, it can also be interpreted as the long-run price elasticity of dividends (Bhargava, 2014).

Theoretically, the stochastic discount factor derived from the intertemporal utility optimization of representative agent is central to pricing future payoffs (Cochrane, 2005). In a log-linearized framework, the stochastic discount factor is linear in the negative discount rate. In the real business cycle $(\mathrm{RBC})$ theory, the real rate can be explained by real consumption growth. In a New Keynesian (NK) framework with sticky prices, the real rate is a component of short term policy rate, which is negatively related to real money balance and can be affected by money growth, inflation rate, nominal interest rate and real output growth (Galí, 2015). Hence, a set of macroeconomic factors and 
shocks can have real impact on stock price movement through the channels of the timevarying discount rate. As a result, the pricing equation can be rewritten as follows, after accounting for the time-varying discount rate using a set of observable macroeconomic variables:

$$
p_{i t}=\gamma+\beta_{1} p_{i, t-1}+\beta_{2} d_{i, t-1}+M_{t} \kappa
$$

where $M_{t}$ is a vector of macroeconomic variables closely related to the discount rate.

\subsection{Econometric representation}

The pricing equation in (8) and (9) can be estimated using linear dynamic panel data methods. We specify two forms of the equation: one with explicit macroeconomic variables closely related to time-varying discount factor, and one with general time effects to capture common shocks, encompassing macroeconomic information on time-varying discount factor and other possible shocks. Considering the possibility of mis-specification of omitted variables or other common shocks to the market, we also estimate an alternative specification with time effects to incorporate macro shocks implicitly.

In both specifications, we allow for firm-specific fixed effects $\alpha_{i}$ and idiosyncratic error term $e_{i t}$. The econometric specifications are as follows:

1. Explicit macro factor specification

$$
p_{i t}=\gamma+\beta_{1} p_{i, t-1}+\beta_{2} d_{i, t-1}+M_{t} \kappa+\alpha_{i}+e_{i t}
$$

For this specification, we consider two sets of macro variables in $M_{t}$ : a small set $M_{t}^{(1)}$, containing a measure of real consumption growth; and a bigger set $M_{t}^{(2)}$, containing measures of real consumption growth, money growth, inflation rate, nominal interest rate and real output growth. Here, we have $M_{t}^{(1)}=\Delta c_{t}$ and $M_{t}^{(2)}=\left[\Delta c_{t}, \Delta M 1_{t}, \Delta C P I_{t}, R_{t}, \Delta G D P_{t}\right]$ and $M_{t}^{(1)}$ and $M_{t}^{(2)}$ captures the stochas- 
tic discount factor in a typical RBC model and a NK model assuming cointegration relationship between these variables respectively. In a simple macro model, consumption growth is often replaced by output growth, but in reality these two variables contain different information in the medium term.

2. Implicit macro factor specification with time effects $\eta_{t}$ :

$$
p_{i t}=\gamma+\beta_{1} p_{i, t-1}+\beta_{2} d_{i, t-1}+\eta_{t}+\alpha_{i}+e_{i t}
$$

In each specification, the correspondence between reduced form parameters and those in the structural model with adaptive expectation can be identified. We can recover structural parameters from the reduced form parameters using minimum distance estimation.

\section{Data}

We obtain all firm-level data from CSMAR (China Stock Market \& Accounting Research) Database, a financial database widely used in the Chinese financial industry and academia. The raw data includes Daily Closing Price (short for "DCP" hereafter), daily Comparable Closing Price with Cash Dividend Reinvested (short for "CCPD" hereafter), daily Comparable Closing Price without Cash Dividend (short for "CCPND" hereafter), and quarterly earnings per share (short for "EPS" hereafter).

To obtain the annual data set, we first get the value of CCPD and CCPND of each company on the last trading day of each year. CCPND is employed as price, while the annual dividend series of each company is obtained following the same method in Bunn and Shiller (2014), which recovers dividends by a combination of CCPD and CCPND.

To obtain the quarterly data set, we first get the value of DCP and CCPND of each company at the last trading day of each quarter. CCPND is employed as price, while 
the quarterly EPS data is adjusted by multiplying the ratio between CCPND and DCP of the same quarter. To make the coefficient on EPS comparable with that on dividend from the annual data set, as well as to eliminate the possible seasonality in companies" earning, we transform the EPS into a trailing-twelve-month measure by summing up the EPS obtained in the past four quarters. Since quarterly information disclosures for a majority of listed firms became more regular after 2006, we restrict our quarterly data set to start from 2006.

All nominal variables including prices and cash flows were inflation-adjusted with 2018 as the base year before taking logarithms. We only selected firms with dividend information for at least 4 years in the annual data set, or with at least 20 observations in the quarterly data set. Since logarithms were used, firms with observations of negative earnings were excluded. With the above selection criteria, we obtain two unbalanced panels, an annual panel of 729 stocks from 1997 to 2018 with a total of 7366 observations, and a quarterly panel of 854 stocks from 2007Q1 to 2019Q2 with a total of 33602 observations.

We obtain the data on related macroeconomic variables, specified in the previous section, from WIND Information Co., Ltd, which is another major financial data company in China. All growth rates are calculated either year-on-year or quarter-on-quarter depending on the dataset. Real consumption growth and real output growth are directly available from the database, while the real growth of M1 and the inflation rate had to be computed from the data on levels. We use the average interbank rate as a proxy for the short-term interest rate. A plot of the resulting quarterly series has been presented in Figure 1.

[Insert Figure 1 here. ] 


\section{Empirical analysis}

\subsection{Estimating the fraction of the panel with an autoregressive unit root}

The models in (10) and (11) may contain variables that are likely to be nonstationary. In practice, it is likely that we encounter a mixed panel where only a proportion of the crosssectional units has an autoregressive unit root. Typically, panel unit root tests would be applied prior to estimating the models in (10) and (11). Unfortunately, these tests are extremely affected by the underlying behavior of the DGPs of each time series that form the panel. We avoid these tests in favor of robust and more informative procedures suggested by Ng (2008) and Westerlund (2016). Both these authors have discussed the value of estimating the fraction of a panel that has an autoregressive unit root.

The procedure is as follows. Let $y_{i t}$ denote the series of interest. In our case, this could refer to log of stock prices or log of dividends.

1. Calculate the cross-sectional variances of $y_{i t}$, i.e., for $t=1, \ldots, T$, we have

$$
V_{t}=\frac{1}{N} \sum_{i=1}^{N}\left(y_{i t}-\bar{y}_{t}\right)^{2}
$$

2. Take the average of the first-differences of the cross-sectional variances in the previous step, i.e.,

$$
\widehat{\theta}=\frac{1}{T} \sum_{t=2}^{T} \Delta V_{t}
$$

3. Divide the previous average by a scaling factor $\widehat{\sigma^{2}}$. This scaling factor is the grand average of the squared residuals $z_{i t}^{2}$ obtained from a time series least squares regres- 
sion of $y_{i t}$ on a constant and $y_{i, t-1}$, i.e.,

$$
\widehat{\sigma^{2}}=\frac{1}{N T} \sum_{i=1}^{N} \sum_{t=2}^{T} z_{i t}^{2}
$$

We then obtain an estimate of the fraction $\widehat{\theta}^{*}=\widehat{\theta} / \widehat{\sigma^{2}}$ of the panel that has an autoregressive unit root.

4. Once $\widehat{\theta}^{*}$ is obtained, find $\left\lfloor\widehat{\theta}^{*} N\right\rfloor$. This will give us the number of cross-sectional units that are deemed to be nonstationary.

5. To classify which of the cross-sectional units are to be deemed nonstationary, we follow a suggestion by $\mathrm{Ng}$ (2008). Order the units by the reciprocal of the estimated $\mathrm{AR}(1)$ coefficient from a time series least squares regression of $y_{i t}$ on a constant and $y_{i, t-1}$. The first $\left\lfloor\widehat{\theta}^{*} N\right\rfloor$ units can be classified as the nonstationary units.

So, we apply the outlined procedure to both log of prices and log of dividends. We then filter out the union of the classified nonstationary units and proceed to estimating (10) and (11). Based on the annual data, our findings indicate that 564 out of the 729 stocks will be used as a subsample for further analysis; while in the quarterly data, 719 out of the 854 stocks will be used. The resulting subset of firms count for about $70.5 \%$ of the total market value of the original annual sample and about $91.9 \%$ of the quarterly sample.

\subsection{Unit root tests applied to macroeconomic variables}

Table 1 shows the $p$-values from augmented Dickey-Fuller tests applied to the quarterly macroeconomic variables. Except for the interest rate, the remaining four series are nonstationary in their levels. We take the first difference of the nonstationary series before including them in $M_{t}^{(1)}$ and $M_{t}^{(2)}$ in (10). From Figure 1, we can trace the nonstation- 
arity to at least two aspects: trending behavior and structural change. For example, real consumption growth and real GDP growth exhibit upward trend before 2008 and a downward trend after 2010; due to the 2008-2009 world financial crisis, real GDP growth and CPI inflation reached their troughs while M1 growth reached a peak, which break the persistent trend.

[Insert Table 1 here.]

\subsection{Correcting the incidental parameter bias}

The dynamic panel data models specified in (10) and (11) involve a relatively large number of stocks $N$ and a moderate number of time periods $T$. It has been widely known in the literature that incidental parameter bias may arise when the number of cross-section units, $N$, grows large but the number of time periods per unit, $T$, remains small (Arellano \& Bonhomme, 2012; Arellano \& Honoré, 2001; Browning \& Carro, 2007; Browning, Ejrnaes, \& Alvarez, 2010; Neyman \& Scott, 1948).

Various methods have been proposed to address such bias in specific models, but mostly require analytical work on the bias which may be computationally complex (Arellano \& Bonhomme, 2009; Arellano \& Hahn, 2006; Hahn \& Kuersteiner, 2011; Hahn \& Newey, 2004; Lancaster, 2002). In an unbalanced panel such as ours, the bias becomes even more complicated to express analytically. Dhaene and Jochmans (2015) (DJ hereafter) propose a split-panel jackknife estimator to correct the bias without requiring an explicit analytical expression for the incidental parameter bias. The split-panel jackknife bias correction method to reproduce an estimate for the parameters, which takes an average of the estimators from two overlapping subpanels to eliminate the first order inconsistency of the original estimator (Dhaene \& Jochmans, 2015). Instead of demonstrating the theoretical relevance of correcting for the incidental parameter bias, we conduct a small Monte Carlo simulation meant to mimic the properties of our dataset- 
s. For interested readers, Appendix A.1 describes the incidental parameter problem for our specific context. Appendix A.2 provides a short exposition on the mechanics of the split-panel jackknife.

We simulate the model in (11) under four scenarios shown in Table 2. In scenarios 1 and 3, balanced panel data sets of annual and quarterly frequencies with dimensions of $\left(N, T_{\max }\right)$ are simulated. For scenarios 2 and 4 , unbalanced panel data sets are obtained by assembling subsets $g$ of simulated balanced data, each with a specific dimension of $\left(N_{g}, T_{g}\right)$, as shown in Table 3 , which closely mimics the unbalancedness patterns present in our actual data. For each scenario, we generate 1000 artificial data sets according to (11), and estimate the parameters for each set with a fixed-effects dynamic panel regression and with the split-panel jackknife.

[ Table 2 to be inserted here. ]

[ Table 3 to be inserted here. ]

Figure 2 plots the densities of the estimated coefficients for $\beta_{1}$ and $\beta_{2}$ for both annual and quarterly datasets, before and after bias correction with the split-panel jackknife.

[ Figure 2 to be inserted here. ]

After correction with the split-panel jackknife, the estimates of $\beta_{1}$, shown in dashed lines, tend to match the true values in all scenarios, as shown in Figure 2. The distributions of $\beta_{2}$ before correction slightly shift to the left with respect to the true values, but the two distributions largely overlap with each other.

Since both structural parameters $c$ and $\delta$ are functions of $\beta_{1}$, the bias in estimating $\beta_{1}$ will be transmitted to the structural parameters as well. Figure 3 plots the distribution of the estimates of the structural parameters obtained from the reduced form estimates of $\beta_{1}$ and $\beta_{2}$. The parameter distributions after correction concentrate around the true values, indicating effectiveness of the correction. 
[ Figure 3 to be inserted here. ]

Table 4 provides a summary of the parameter bias in percentage terms. The simulation study shows that the incidental parameter bias in this dynamic panel data model is quite large and could not be ignored. The biases in the estimation of the reduced form parameters greatly affect the estimation of the structural parameters. The most relevant for our context is the price elasticity of dividends $\delta$, which measures the long-run fundamental impact of cash flows. Its bias is sizable and does not necessarily decrease with larger sample size as a result of having measurements at a higher frequency. Thus, bias correction is a step that cannot be ignored, otherwise the economic interpretation of the price elasticity and speed of expectation adjustment can be dramatically different from the underlying values.

[ Table 4 to be inserted here. ]

\subsection{Estimation results for (10) and (11)}

We estimate the model specifications in (10) and (11) for both annual and quarterly panels. For each regression, we report the results before and after bias correction. Table 5 and Table 6 report the regression results for annual and quarterly data, respectively.

[ Table 5 to be inserted here. ]

[ Table 6 to be inserted here. ]

Based on the regression results in Tables 5 and 6, we find that, broadly, firm-specific fundamentals are priced, as $\beta_{1}$ and $\beta_{2}$ are statistically different from zero. The loadings for some of the macroeconomic variables are in line with economic theory, but they can be sensitive to whether the annual or quarterly datasets are used. In fact, the loading 
on interest rate $R_{t}$ changes dramatically after bias correction based on the results for the annual data.

Just as we have observed in the small simulation study in a previous subsection, the small differences in the reduced form estimates generate substantial differences in the estimates of the structural parameters. In terms of whether there is evidence consistent with rational expectation formation as opposed to adaptive expectation formation, we find that $c$ is both economically and statistically different from one. Furthermore, the price elasticity of dividends is statistically different from zero. These findings are robust to whether we look at annual or quarterly data, and whether or not we applied bias correction procedures.

Although the price elasticity of dividend in all regressions are statistically below 1 even after bias correction, it has substantial economic significance due to the extraordinary level of PE and PD ratios in the Shanghai Stock Exchange. Based on our annual data, the medians of real price, real dividend, and PD ratio are 38 yuan, 0.37 yuan and 94, respectively. Back-of-the-envelope calculations indicate that, given the elasticity of 0.46 after bias correction, when dividend per-share increases by 5 cents, the price is expected to increase by approximately 2.37 yuan, an over 40-fold sizable pricing effect. In contrast, had we used the elasticity of 0.32 before bias correction, then the estimated price change will be about 1.64 yuan, which results in a $30 \%$ underestimation of the price change. The resulting underpricing is substantial in economic terms.

\subsection{The macro factors and time effects}

In the regression analysis, we find that most of the macroeconomic variables related to time-varying discount rate are significantly priced. However, the time effects representation is more comprehensive with macroeconomic shocks and other shocks. To show this, we plot the time effects and the effects explained by macro factors, $M_{t} \kappa$, in Figure 4 . The 
correlations between the two parts are reported in Table 7. We can see from Figure 4 that the macro effects are correlated with the time effects in both annual and quarterly data sets, with the former showing higher correlation. Macro factors estimated using $M_{t}^{(2)}$ have higher correlation with the time effect than $M_{t}^{(1)}$. According to Table 7 , in the annual data regression, the correlation between macro factors on $M_{t}^{(2)}$ reaches 0.42 , while that with macro factors on $M_{t}^{(1)}$ is only 0.22 ; in the quarterly data regression, the correlation of time effect with macro factors on $M_{t}^{(1)}$ and $M_{t}^{(2)}$ are 0.11 and 0.46 , respectively. The macro effects are much smoother, which does not fully capture large shocks such as the 2008 financial crisis or the 2015 market surge under optimistic expectation and government stimulus. Thus, the time effect specification may be a better modeling choice.

[ Figure 4 to be inserted here. ]

[ Table 7 to be inserted here. ]

\subsection{Discussion}

Is there evidence that fundamentals are priced for listed stocks at the SSEC Index? Based on our results, the answer is yes. But why do prices fluctuate so dramatically and sometimes seemingly "bubble-like"? From the estimation results of the DDM with adaptive expectation, the explanation can be traced to two reasons: the presence of large shocks and the slow adjustment of expectations.

1. Large shocks: From plots of time effects in Figure 7, we know that the common shocks are neither persistent nor "bubble-like". The autocorrelation of implicit time effects defined in equation (11) are -0.25 in annual data set and 0.14 in quarterly data set, both are insignificant at the 5\% significance level. However, the shocks are huge relative to prices. Measured in relative terms to log price, the variance of 
shocks account for $21 \%$ of the median variance of prices in quarterly data, and $46 \%$ in annual data.

2. Slow adjustment in expectations: The slow adjustment in expectation in the structural model determines the persistence of the price dynamics in the reduced form, because $c=1-\beta_{1}$, which gives rise to the price persistence from the investors' expectation formation. The persistence together with large shocks will generate "bubbly" price patterns.

\section{Conclusion}

As the Chinese stock market grows rapidly with its remarkable economic development in the past two decades, it is important to understand the pricing mechanisms and the fundamental effects in this market. But its volatile and speculative price movement tends to dwarf fundamental values reflected in prices. In this paper, we demonstrate a technical aspect that may downplay fundamental pricing even by using a large panel data of individual firms to amend the limited information with aggregate historical data. We point out the necessity to apply proper method of bias correction in the context of such asset pricing problems with panel models.

In particular, we show that the rich information in a panel model does not necessarily guarantee a correct inference of the fundamental impact of cash flows. The incidental parameter biases can be moderate in the price persistence parameter in the reducedform model, but implies a substantial bias in the structural parameters. For example, the downward bias in price elasticity is a sizable $30 \%$. Moreover, we find that more observations from higher frequency data may not alleviate the problem, which needs to be carefully treated with bias correction method.

Our work also provides an explanation on the "casino" pricing feature in the Chinese 
stock market by introducing adaptive expectation. Slow adjustment in expectation leads to price persistence. Together with large shocks, being external or internal, the price reaction becomes "bubble" like.

\section{Appendix}

\section{A1. Incidental parameter problem}

This section gives a brief description on the incidental parameter problem, following Fernández-Val and Weidner (2018).

A standard panel data model with $N$ individuals and time length $T$ is:

$$
y_{i t}=\beta_{0} x_{i t}+\alpha_{i}+\eta_{t}+\varepsilon_{i t}
$$

where, $E\left(\varepsilon_{i t} \mid X_{i 1}, \cdots, X_{i t}, \alpha, \eta\right)=0, \alpha=\left(\alpha_{1}, \cdots, \alpha_{N}\right), \eta=\left(\eta_{1}, \cdots, \eta_{T}\right)$. The panel data set is assumed to be large on both dimensions: $T, N \rightarrow \infty, \frac{N}{T} \rightarrow p$. Denote $\hat{\beta}_{N T}$ as the standard OLS estimator on $\beta_{0}$ based on the full sample with cross-section $\mathrm{N}$ and time $\operatorname{span} \mathrm{T}$ :

$$
\hat{\beta}_{N T}=\left(\sum_{i=1}^{N} \sum_{t=1}^{T} \tilde{x}_{i t} \tilde{x}_{i t}^{\prime}\right)^{-1}\left(\sum_{i=1}^{N} \sum_{t=1}^{T} \tilde{x}_{i t} \tilde{y}_{i t}\right)
$$

where $\tilde{x}_{i t}$ and $\tilde{y}_{i t}$ represent residuals of the linear projection of $x_{i t}$ and $y_{i t}$ on the space spanned by the individual and time effects. According to Fernández-Val and Weidner (2017), the asymptotic distribution of $\hat{\beta}_{N T}$ follows:

$$
\sqrt{N T}\left(\hat{\beta}-\beta_{0}-\frac{B}{T}-\frac{D}{N}\right) \stackrel{d}{\rightarrow} N\left(0, H^{-1}\right)
$$


where

$$
\begin{aligned}
& B=H^{-1} \operatorname{plim}_{N, T \rightarrow \infty}-E_{N T} \sum_{s=t+1}^{T} \varepsilon_{i t} \tilde{x}_{i s} \\
& D=0 \text { for the linear setting } \\
& H=\operatorname{plim}_{N, T \rightarrow \infty} E_{N T}\left\{\tilde{x}_{i t} \tilde{x}_{i t}\right\}
\end{aligned}
$$

It is obvious that: under $T, N \rightarrow \infty, \frac{N}{T} \rightarrow p, \hat{\beta}$ gives a consistent estimate on $\beta_{0}$, however, there exists an asymptotic bias problem because the asymptotic distribution of $\hat{\beta}$ does not center around $\beta_{0}$, thus a bias correction is necessary.

\section{A2. Split sample jackknife bias correction}

In this paper, the split sample jackknife bias correction is employed to conduct the bias correction. The method is introduced by Quenouille (1949) for time series data, and then extended to panel data with individual effect (Dhaene \& Jochmans, 2015) and both individual and time effects (Fernández-Val \& Weidner, 2016). Here we briefly describe the way to construct the bias corrected estimator, following Fernández-Val and Weidner (2018).

According to equation 14, the bias only exists in the mean of the asymptotic distribution, the asymptotic variance is not affected. Thus, the only issue is to correct the estimator so that it centers at the right value. Let $\hat{\beta}_{S B C}$ denote the estimation on $\beta_{0}$ after bias correction, and it can be calculated as:

$$
\begin{aligned}
\hat{\beta}_{S B C} & =3 \hat{\beta}_{N T}-\hat{\beta}_{N / 2, T}-\hat{\beta}_{N, T / 2} \\
\hat{\beta}_{N / 2, T} & =\frac{1}{2}\left[\hat{\beta}_{\{i \leq\lceil N / 2\rceil, T\}}+\hat{\beta}_{\{i \geq\lfloor N / 2+1\rfloor, T\}}\right] \\
\hat{\beta}_{N, T / 2} & =\frac{1}{2}\left[\hat{\beta}_{\{N, t \leq\lceil T / 2\rceil\}}+\hat{\beta}_{\{N, t \geq\lfloor T / 2+1\rfloor\}}\right]
\end{aligned}
$$


Again, we use subscripts to label the sample period with which the coefficient is estimated. $\hat{\beta}_{N / 2, T}$ indicates an estimation on $\beta_{0}$ with observations of half the individuals, which is calculated by splitting the whole sample into two halves based on the individual dimension, running the $\hat{\beta}$ estimation on each sub-sample, and taking average of them. Similar method is employed to estimate $\hat{\beta}_{N, T / 2}$, except that the sample is split on the time dimension rather than the individual dimension. 


\section{References}

Arellano, M., \& Bonhomme, S. (2009). Robust priors in nonlinear panel data models. Econometrica, $77(2), 489-536$.

Arellano, M., \& Bonhomme, S. (2012). Identifying distributional characteristics in random coefficients panel data models. The Review of Economic Studies, 79(3), 9871020.

Arellano, M., \& Hahn, J. (2006). A likelihood-based approximate solution to the incidental parameter problem in dynamic nonlinear models with multiple effects. Unpublished manuscript.

Arellano, M., \& Honoré, B. (2001). Panel data models: some recent developments. In Handbook of econometrics (Vol. 5, pp. 3229-3296). Elsevier.

Bhargava, A. (2014). Firms' fundamentals, macroeconomic variables and quarterly stock prices in the us. Journal of Econometrics, 183(2), 241-250.

Browning, M., \& Carro, J. (2007). Heterogeneity and microeconometrics modeling. In R. Blundell, W. Newey, \& T. Persson (Eds.), Advances in economics and econometrics: Theory and applications, ninth world congress (Vol. 3, p. 47-74). Cambridge University Press. doi: 10.1017/CBO9780511607547.004

Browning, M., Ejrnaes, M., \& Alvarez, J. (2010). Modelling income processes with lots of heterogeneity. The Review of Economic Studies, r7y(4), 1353-1381.

Bunn, O. D., \& Shiller, R. J. (2014). Changing times, changing values: A historical analysis of sectors within the us stock market 1872-2013 (Tech. Rep.). National Bureau of Economic Research.

Campbell, J. Y., \& Shiller, R. J. (1988). Stock prices, earnings, and expected dividends. The Journal of Finance, 43(3), 661-676.

Carpenter, J. N., Lu, F., \& Whitelaw, R. F. (2018). The real value of china's stock market. BOFIT Discussion Papers, 2018(2), 0_3-37. 
Choi, J. J., Jin, L., \& Yan, H. (2012, 10). What Does Stock Ownership Breadth Measure?*. Review of Finance, 17(4), 1239-1278. Retrieved from https://doi.org/ 10.1093/rof/rfs026 doi: 10.1093/rof/rfs026

Chow, G. (1989). Rational versus adaptive expectations in present value models. The Review of Economics and Statistics, 71(3), 376-84.

Cochrane, J. H. (2005). Asset pricing (revised edition). Princeton university press.

Cochrane, J. H. (2007). The dog that did not bark: A defense of return predictability. The Review of Financial Studies, 21(4), 1533-1575.

Cochrane, J. H. (2011). Presidential address: Discount rates. The Journal of finance, $66(4), 1047-1108$.

Cohen, R. B., Polk, C., \& Vuolteenaho, T. (2009). The price is (almost) right. The Journal of Finance, 64(6), 2739-2782. Retrieved from https://onlinelibrary .wiley.com/doi/abs/10.1111/j.1540-6261.2009.01516.x doi: https://doi $. \operatorname{org} / 10.1111 / \mathrm{j} .1540-6261.2009 .01516 . \mathrm{x}$

Dhaene, G., \& Jochmans, K. (2015). Split-panel jackknife estimation of fixed-effect models. The Review of Economic Studies, 82(3), 991-1030.

Favero, C. A., Melone, A., \& Tamoni, A. (2020). Factor models with drifting prices. Available at SSRN: https://ssrn.com/abstract=3418352 or http://dx.doi.org/10.2139/ssrn.3418352.

Fernández-Val, I., \& Weidner, M. (2016). Individual and time effects in nonlinear panel models with large n, t. Journal of Econometrics, 192(1), 291-312.

Fernández-Val, I., \& Weidner, M. (2018). Fixed effects estimation of large-t panel data models. Annual Review of Economics, 10, 109-138.

Galí, J. (2015). Monetary policy, inflation, and the business cycle: an introduction to the new keynesian framework and its applications. Princeton University Press.

Gordon, M. (1962). The investment, financing, and valuation of the corporation. R.D. 
Irwin.

Gul, F. A., Kim, J.-B., \& Qiu, A. A. (2010). Ownership concentration, foreign shareholding, audit quality, and stock price synchronicity: Evidence from china. Journal of Financial Economics, 95(3), 425 - 442. Retrieved from http://www .sciencedirect.com/science/article/pii/S0304405X09002359 doi: https:// doi.org/10.1016/j.jfineco.2009.11.005

Hahn, J., \& Kuersteiner, G. (2011). Bias reduction for dynamic nonlinear panel models with fixed effects. Econometric Theory, 27(6), 1152-1191.

Hahn, J., \& Newey, W. (2004). Jackknife and analytical bias reduction for nonlinear panel models. Econometrica, 72(4), 1295-1319.

Hasan, I., Song, L., \& Wachtel, P. (2014). Institutional development and stock price synchronicity: Evidence from china. Journal of Comparative Economics, 42(1), 92 - 108. Retrieved from http://www.sciencedirect.com/science/article/pii/ S014759671300108X doi: https://doi.org/10.1016/j.jce.2013.07.006

Kong, D., Lin, C., \& Liu, S. (2017, 06). Does Information Acquisition Alleviate Market Anomalies? Categorization Bias in Stock Splits*. Review of Finance, 23(1), 245277. Retrieved from https://doi.org/10.1093/rof/rfx028 doi: 10.1093/rof/ $\operatorname{rfx} 028$

Lancaster, T. (2002). Orthogonal parameters and panel data. The Review of Economic Studies, 69(3), 647-666.

Liu, J., Stambaugh, R. F., \& Yuan, Y. (2019). Size and value in china. Journal of Financial Economics, 134(1), 48 - 69. doi: https://doi.org/10.1016/j.jfineco.2019 .03 .008

Mei, J., Scheinkman, J., \& Xiong, W. (2009). Speculative trading and stock prices: Evidence from chinese ab share premia. Annals of Economics and Finance, 10(2), $225-255$. 
Morck, R., Yeung, B., \& Yu, W. (2000). The information content of stock markets: why do emerging markets have synchronous stock price movements? Journal of Financial Economics, 58(1), 215 - 260. Retrieved from http://www.sciencedirect.com/ science/article/pii/S0304405X00000714 (Special Issue on International Corporate Governance) doi: https://doi.org/10.1016/S0304-405X(00)00071-4

Newey, W. K., \& West, K. D. (1987). A simple, positive semi-definite, heteroskedasticity and autocorrelation consistent covariance matrix. Econometrica, 55(3), 703-708. Retrieved from http://www.jstor.org/stable/1913610

Neyman, J., \& Scott, E. L. (1948). Consistent estimates based on partially consistent observations. Econometrica, 16(1), 1-32.

Ng, S. (2008). A simple test for nonstationarity in mixed panels. Journal of Business $\&$ Economic Statistics, 26(1), 113-127. Retrieved from https://doi.org/10.1198/ 073500106000000675 doi: 10.1198/073500106000000675

Poterba, J. M., \& Summers, L. H. (1988). Mean reversion in stock prices: Evidence and implications. Journal of Financial Economics, 22(1), 27 59. Retrieved from http://www.sciencedirect.com/science/article/pii/ 0304405X88900219 doi: https://doi.org/10.1016/0304-405X(88)90021-9

Quenouille, M. (1949). Approximate tests of correlation in time-series. Journal of the Royal Statistical Society: Series B (Methodological), 11(1), 68-84.

Westerlund, J. (2016). A simple test for nonstationarity in mixed panels: A further investigation. Journal of Statistical Planning and Inference, 173, 1-30. Retrieved from http://www.sciencedirect.com/science/article/pii/ S0378375816000057 doi: 10.1016/j.jspi.2016.01.004

Xiong, W., \& Yu, J. (2011). The chinese warrants bubble. American Economic Review, $101(6), 2723-53$. 
Figure 1: China's economic indicators (1996Q4-2019Q2)
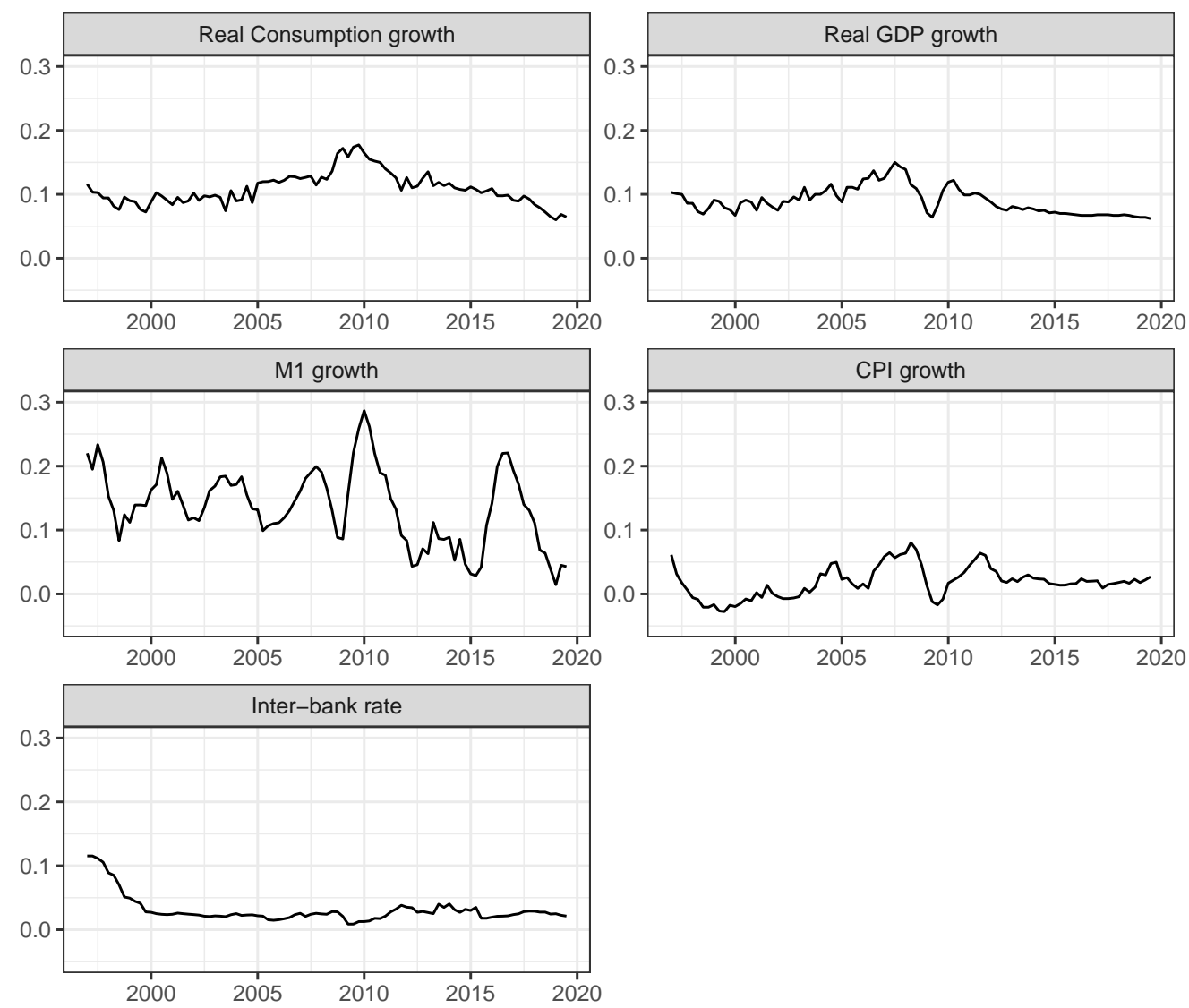

Year-on-year growth rates were calculated, except for the inter-bank rate, which is in levels. 
Figure 2: Reduced-form parameter distributions

a) Annual Data

1) Balanced panel
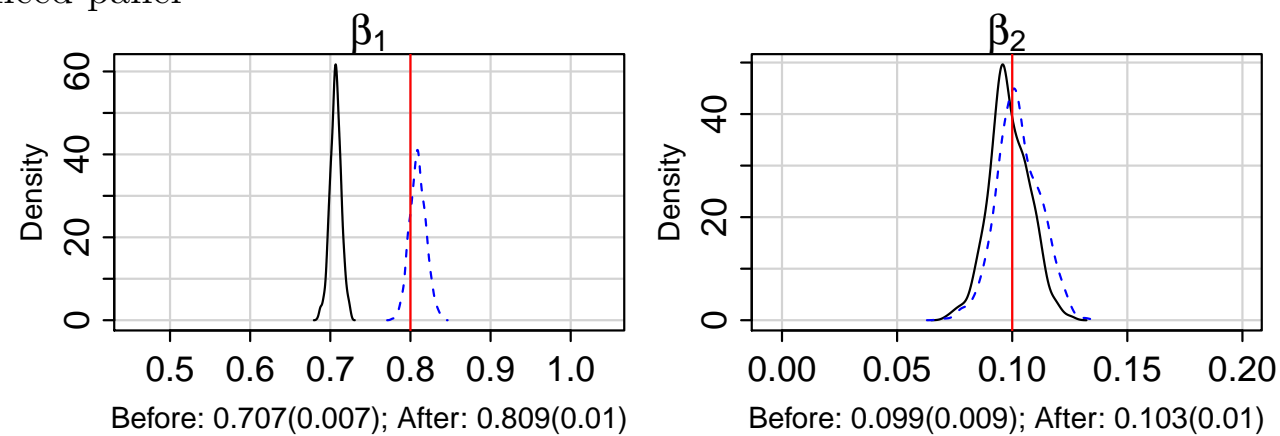

2) Unbalanced panel
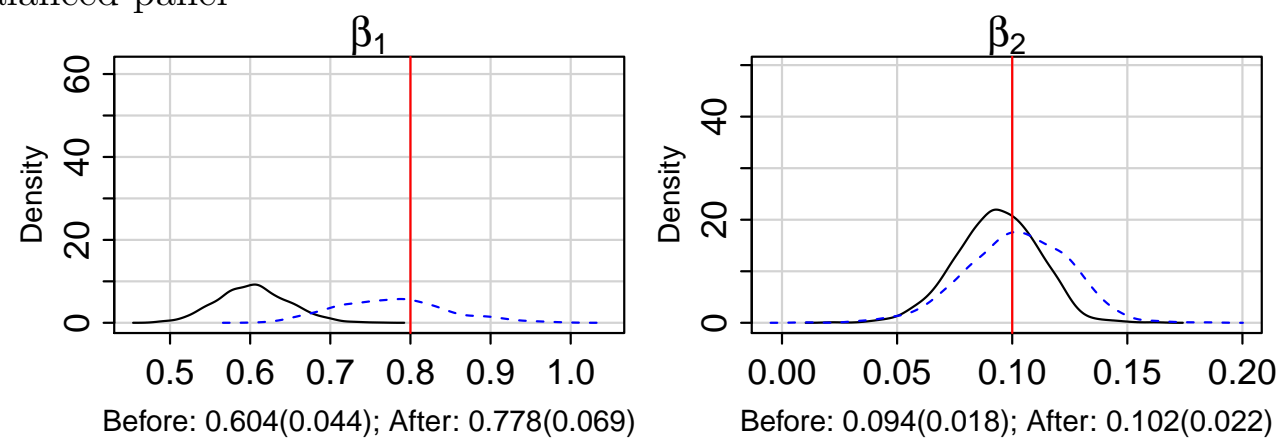

b) Quarterly Data

3) Balanced panel
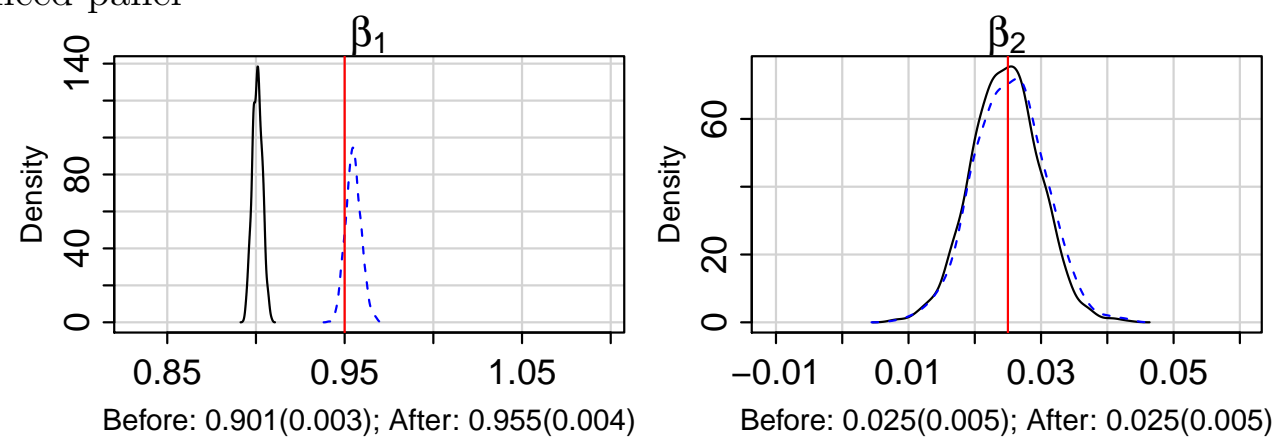

4) Unbalanced panel
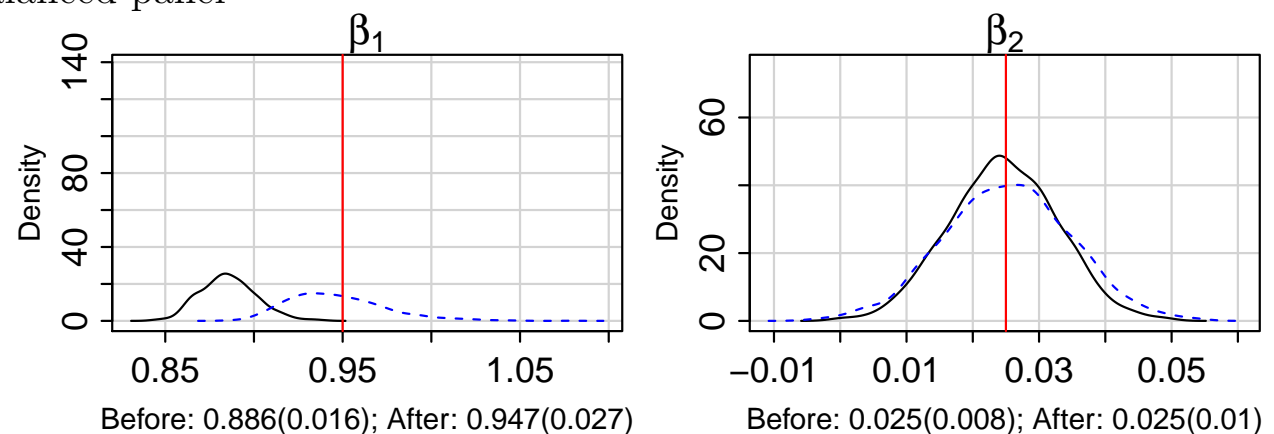

Note: In each panel, the black solid line indicates the density of estimated coefficients before bias correction, while the blue dashed line indicates the one after bias correction. The red vertical line indicates the position offthe true value. Below each panel, we report the median and variance in bracket for the parameter density before and after correction. 
Figure 3: Structural parameter distributions

a) Annual Data

1) Balanced panel
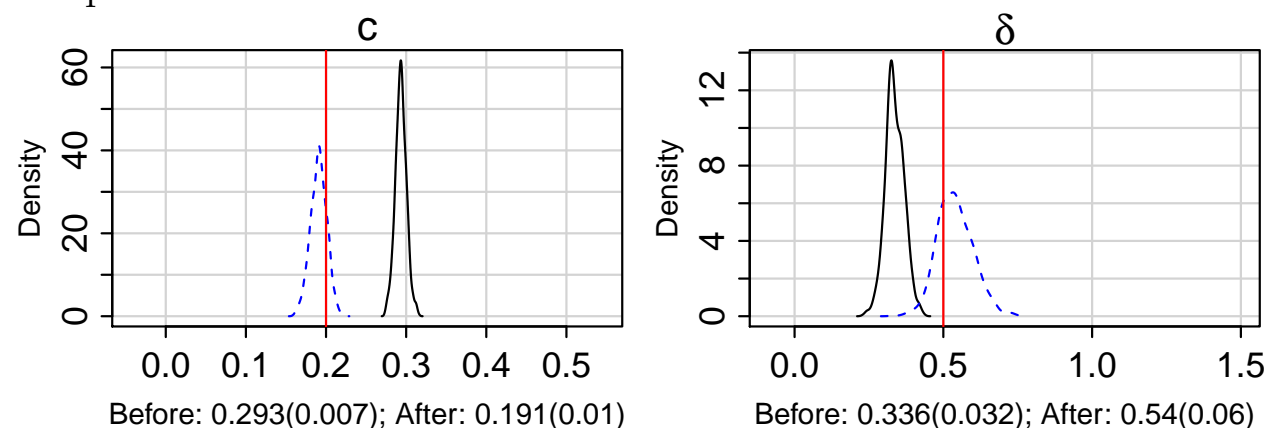

2) Unbalanced panel
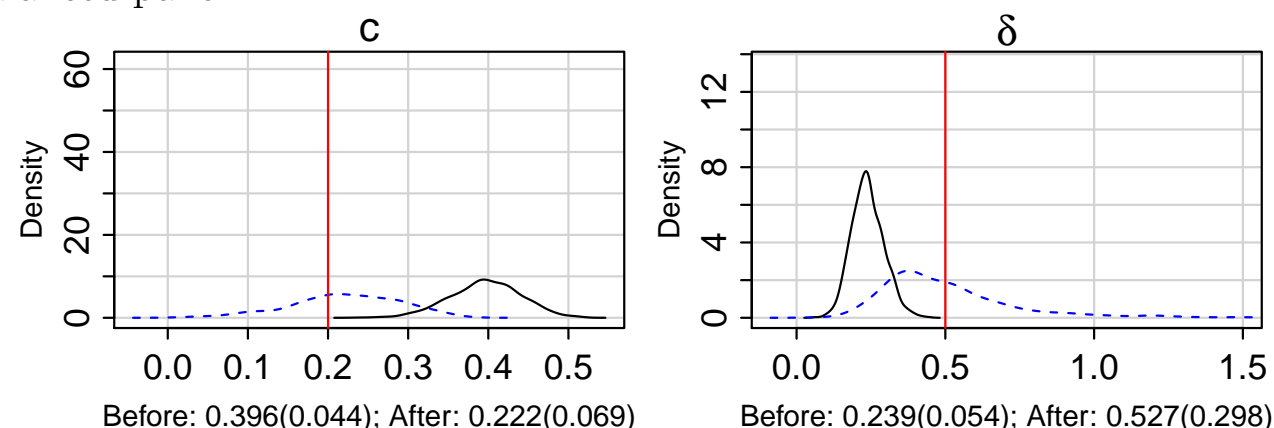

Before: 0.396(0.044); After: 0.222(0.069)

Before: 0.239(0.054); After: 0.527(0.298)

b) Quarterly Data

3) Balanced panel
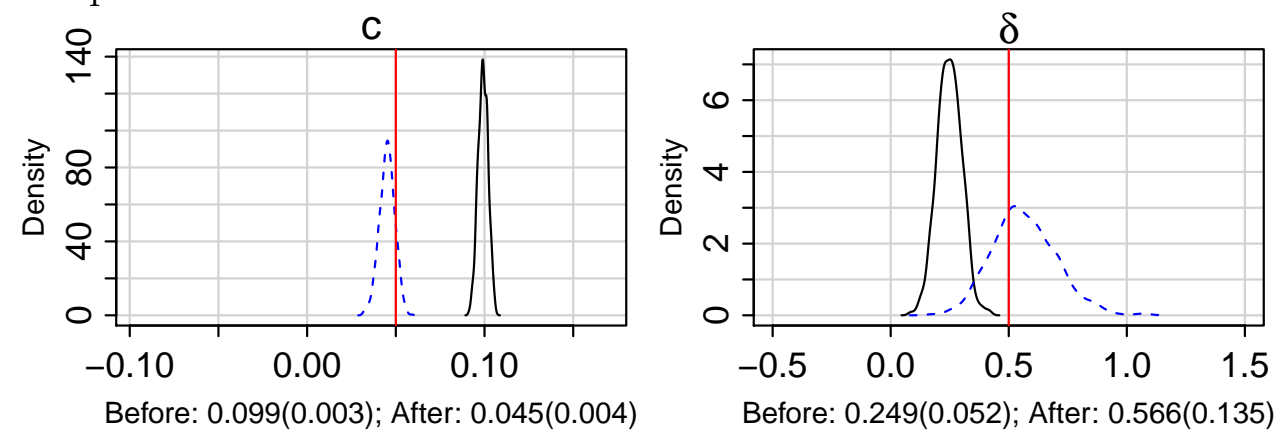

4) Unbalanced panel
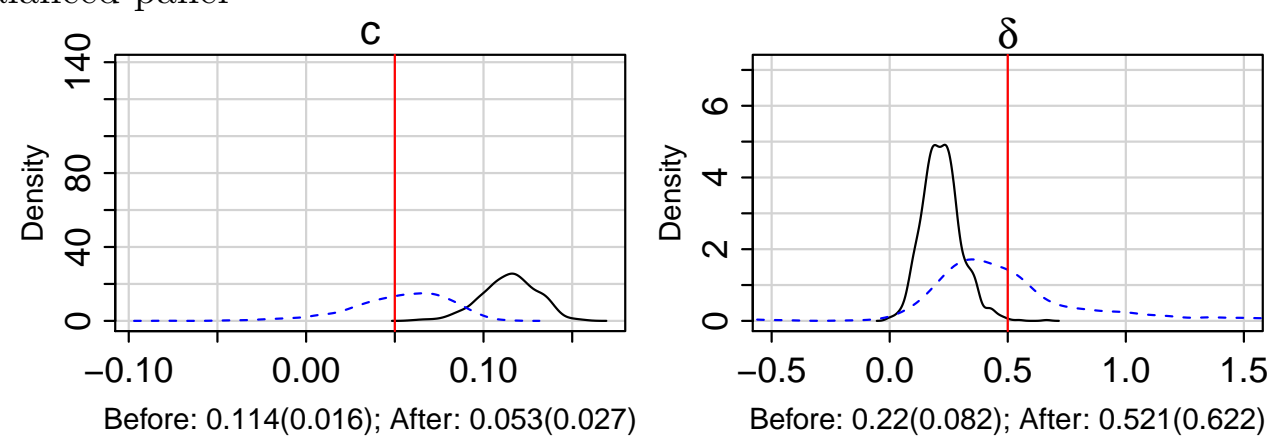

Note: In each panel, the black solid line indicates the density of estimated coefficients before bias correction, while the blue dashed line indicates the one after bias correction. The red vertical line indicates the position of 8 the true value. Below each panel, we report the median and variance in bracket for the parameter density before and after correction. 
Figure 4: The time effects and macro factor effects

a) Annual Data

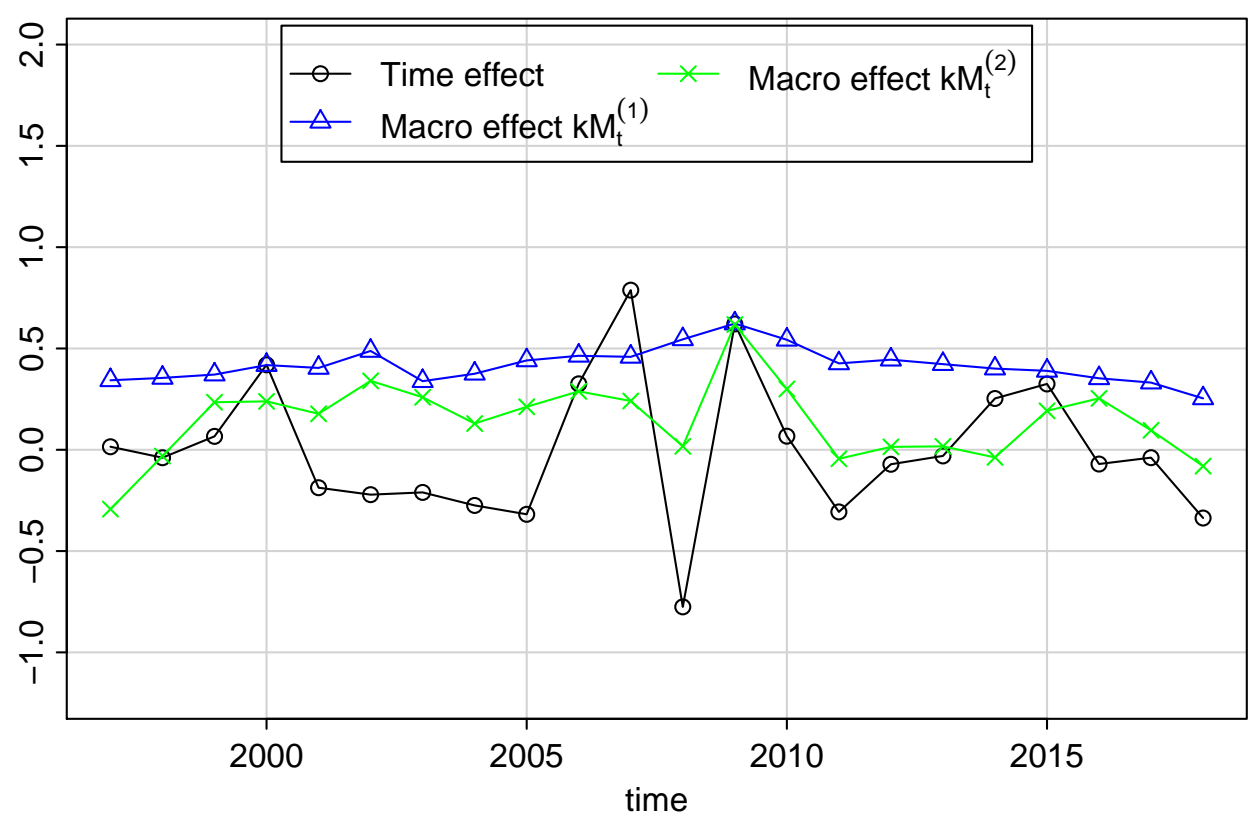

b) Quarterly Data

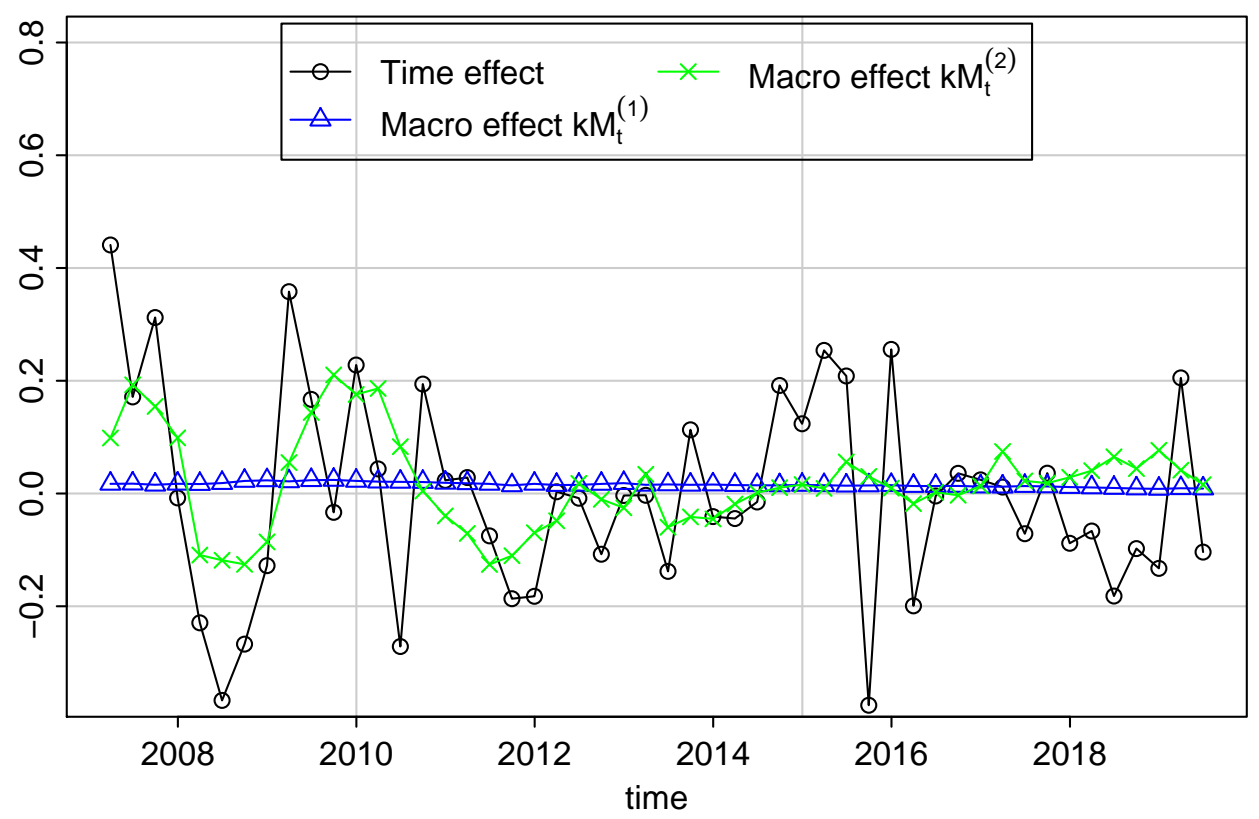


Table 1: $p$-values of ADF test on quarterly macro variables

\begin{tabular}{llcc}
\hline \hline & Variables & Level & First-difference \\
\hline \multirow{4}{*}{ Quarterly } & $c_{t}$ & 0.954 & 0.010 \\
& $M 1_{t}$ & 0.178 & 0.010 \\
& $C P I_{t}$ & 0.567 & 0.010 \\
& $G D P_{t}$ & 0.327 & 0.010 \\
& $R_{t}$ & 0.010 & 0.207 \\
\hline \hline
\end{tabular}

Note: For each macro series, the ADF test is conducted on both the raw series and its first difference. The significance level is $\alpha=0.05$.

Table 2: Simulation scenarios

\begin{tabular}{c|c|c|c}
\hline \hline & Parameters & Balanced & Unbalanced \\
\hline \multirow{3}{*}{ Annual } & $\begin{array}{c}N=564, T_{\max }=22 \\
(c, \delta)=(0.2,0.5) \\
\text { or }\left(\beta_{1}, \beta_{2}\right)=(0.8,0.1)\end{array}$ & Scenario 1 & Scenario 2 \\
\hline \multirow{3}{*}{ Quarterly } & $\begin{array}{c}N=719, T_{\max }=50 \\
(c, \delta)=(0.05,0.5) \\
\end{array}$ & Scenario 3 & Scenario 4 \\
& or $\left(\beta_{1}, \beta_{2}\right)=(0.95,0.025)$ & & \\
\hline \hline
\end{tabular}

Table 3: Simulation designs on the time span composition in unbalanced panels

a) Scenario 2 (Annual)

\begin{tabular}{c|cccccccccc}
\hline \hline Group g & 1 & 2 & 3 & 4 & 5 & 6 & 7 & 8 & 9 & 10 \\
\hline$N_{g}$ & 86 & 113 & 77 & 73 & 63 & 29 & 60 & 46 & 15 & 2 \\
$T_{g}$ & 4 & 7 & 8 & 10 & 12 & 14 & 16 & 18 & 19 & 22 \\
\hline \hline
\end{tabular}

b) Scenario 4 (Quarterly)

\begin{tabular}{c|cccccccccc}
\hline \hline Group g & 1 & 2 & 3 & 4 & 5 & 6 & 7 & 8 & 9 & 10 \\
\hline$N_{g}$ & 34 & 33 & 40 & 59 & 41 & 57 & 63 & 77 & 112 & 203 \\
$T_{g}$ & 20 & 24 & 28 & 30 & 34 & 36 & 40 & 42 & 46 & 50 \\
\hline \hline
\end{tabular}


Table 4: Summary of estimation biases: Percentage deviation (\%) from the true value a) On reduced-form parameters

\begin{tabular}{cccc}
\hline \hline \multirow{2}{*}{ Parameter } & \multirow{2}{*}{ Frequency } & \multicolumn{2}{c}{ Simulation } \\
\cline { 3 - 4 } & & Balanced & Unbalanced \\
\hline \multirow{2}{*}{$\beta_{1}$} & Annual & -11.6 & -24.5 \\
& Quarterly & -5.16 & -6.74 \\
\hline \hline
\end{tabular}

b) On structural parameters

\begin{tabular}{cccc}
\hline \hline \multirow{2}{*}{ Parameter } & \multirow{2}{*}{ Frequency } & \multicolumn{2}{c}{ Simulation } \\
\cline { 3 - 4 } & & Balanced & Unbalanced \\
\hline \multirow{2}{*}{$c$} & Annual & 46.5 & 98 \\
& Quarterly & 98 & 128 \\
\hline \multirow{2}{*}{$\delta$} & Annual & -32.8 & -52.2 \\
& Quarterly & -50.2 & -56 \\
\hline \hline
\end{tabular}


Table 5: Estimation result with annual data $\left(N=564, T_{\max }=22\right)$

\begin{tabular}{|c|c|c|c|c|c|c|}
\hline & \multicolumn{4}{|c|}{ Eq. (10) } & \multirow{2}{*}{\multicolumn{2}{|c|}{$\begin{array}{l}\text { Eq. (11) } \\
\text { Implicit }\end{array}$}} \\
\hline & \multicolumn{2}{|c|}{$M_{t}^{1}$} & \multicolumn{2}{|c|}{$M_{t}^{2}$} & & \\
\hline & before & after & before & after & before & after \\
\hline \multicolumn{7}{|c|}{ Reduced Form Parameters } \\
\hline \multirow[t]{2}{*}{$\beta_{1}$} & 0.579 & 0.579 & 0.638 & 0.641 & 0.624 & 0.768 \\
\hline & $(0.012)$ & $(0.012)$ & $(0.013)$ & $(0.013)$ & $(0.012)$ & $(0.012)$ \\
\hline \multirow[t]{2}{*}{$\beta_{2}$} & 0.248 & 0.249 & 0.238 & 0.242 & 0.119 & 0.106 \\
\hline & $(0.008)$ & $(0.008)$ & $(0.008)$ & $(0.008)$ & $(0.006)$ & $(0.006)$ \\
\hline \multirow[t]{2}{*}{$\Delta c_{t}$} & 3.696 & 3.676 & 0.955 & 0.755 & & \\
\hline & $(0.214)$ & $(0.214)$ & $(0.314)$ & $(0.314)$ & & \\
\hline \multirow[t]{2}{*}{$\Delta M 1_{t}$} & & & 1.992 & 1.598 & & \\
\hline & & & $(0.106)$ & $(0.106)$ & & \\
\hline \multirow[t]{2}{*}{$\Delta G D P_{t}$} & & & 1.065 & 0.779 & & \\
\hline & & & $(0.532)$ & $(0.532)$ & & \\
\hline \multirow[t]{2}{*}{$\triangle C P I_{t}$} & & & -3.639 & -2.773 & & \\
\hline & & & $(0.447)$ & $(0.447)$ & & \\
\hline \multirow[t]{2}{*}{$R_{t}$} & & & 2.904 & -5.711 & & \\
\hline & & & $(0.696)$ & $(0.696)$ & & \\
\hline \multicolumn{7}{|c|}{ Structural Parameters } \\
\hline \multirow[t]{2}{*}{$c$} & 0.421 & 0.421 & 0.362 & 0.359 & 0.376 & 0.232 \\
\hline & $(0.012)$ & $(0.012)$ & $(0.013)$ & $(0.013)$ & $(0.012)$ & $(0.012)$ \\
\hline \multirow[t]{2}{*}{$\delta$} & 0.590 & 0.591 & 0.656 & 0.673 & 0.318 & 0.459 \\
\hline & $(0.020)$ & $(0.020)$ & $(0.027)$ & $(0.028)$ & $(0.016)$ & $(0.028)$ \\
\hline \multicolumn{7}{|c|}{ Individual effect } \\
\hline \multirow{2}{*}{$\begin{array}{c}\text { controlled } \\
\text { corrected }\end{array}$} & yes & yes & yes & yes & yes & yes \\
\hline & no & yes & no & yes & no & yes \\
\hline \multicolumn{7}{|l|}{ Time effect } \\
\hline controlled & no & no & no & no & yes & yes \\
\hline corrected & no & no & no & no & no & yes \\
\hline
\end{tabular}

Note: Newey and West (1987) robost standard errors are reported in parentheses. 
Table 6: Estimation result with quarterly data $\left(N=719, T_{\max }=50\right)$

\begin{tabular}{|c|c|c|c|c|c|c|}
\hline & \multicolumn{4}{|c|}{ Eq. (10) } & \multirow{2}{*}{\multicolumn{2}{|c|}{$\begin{array}{l}\text { Eq. (11) } \\
\text { Implicit }\end{array}$}} \\
\hline & \multicolumn{2}{|c|}{$M_{t}^{1}$} & \multicolumn{2}{|c|}{$M_{t}^{2}$} & & \\
\hline & before & after & before & after & before & after \\
\hline \multicolumn{7}{|c|}{ Reduced Form Parameters } \\
\hline \multirow[t]{2}{*}{$\beta_{1}$} & 0.807 & 0.807 & 0.798 & 0.798 & 0.859 & 0.925 \\
\hline & $(0.004)$ & $(0.004)$ & $(0.004)$ & $(0.004)$ & $(0.003)$ & $(0.003)$ \\
\hline \multirow[t]{2}{*}{$\beta_{2}$} & 0.030 & 0.030 & 0.035 & 0.035 & 0.030 & 0.026 \\
\hline & $(0.002)$ & $(0.002)$ & $(0.002)$ & $(0.002)$ & $(0.002)$ & $(0.002)$ \\
\hline \multirow[t]{2}{*}{$\Delta c_{t}$} & 0.133 & 0.136 & -2.081 & -2.084 & & \\
\hline & $(0.050)$ & $(0.050)$ & $(0.069)$ & $(0.069)$ & & \\
\hline \multirow[t]{2}{*}{$\Delta M 1_{t}$} & & & -0.053 & -0.054 & & \\
\hline & & & $(0.027)$ & $(0.027)$ & & \\
\hline \multirow[t]{2}{*}{$\Delta G D P_{t}$} & & & 5.436 & 5.459 & & \\
\hline & & & $(0.139)$ & $(0.139)$ & & \\
\hline \multirow[t]{2}{*}{$\triangle C P I_{t}$} & & & -5.197 & -5.211 & & \\
\hline & & & $(0.139)$ & $(0.139)$ & & \\
\hline \multirow[t]{2}{*}{$R_{t}$} & & & -2.183 & -2.168 & & \\
\hline & & & $(0.234)$ & $(0.234)$ & & \\
\hline \multicolumn{7}{|c|}{ Structural Parameters } \\
\hline \multirow[t]{2}{*}{$c$} & 0.193 & 0.193 & 0.202 & 0.202 & 0.141 & 0.075 \\
\hline & $(0.004)$ & $(0.004)$ & $(0.004)$ & $(0.004)$ & $(0.003)$ & $(0.003)$ \\
\hline \multirow[t]{2}{*}{$\delta$} & 0.157 & 0.157 & 0.175 & 0.175 & 0.211 & 0.349 \\
\hline & $(0.011)$ & $(0.011)$ & $(0.009)$ & $(0.009)$ & $(0.010)$ & $(0.019)$ \\
\hline \multicolumn{7}{|c|}{ Individual effect } \\
\hline \multirow{2}{*}{$\begin{array}{c}\text { controlled } \\
\text { corrected }\end{array}$} & yes & yes & yes & yes & yes & yes \\
\hline & no & yes & no & yes & no & yes \\
\hline \multicolumn{7}{|l|}{ Time effect } \\
\hline controlled & no & no & no & no & yes & yes \\
\hline corrected & no & no & no & no & no & yes \\
\hline
\end{tabular}

Note: Newey and West (1987) robost standard errors are reported in parentheses. 
Table 7: Correlation between the time effects and macro factor effects

a) Annual data

\begin{tabular}{c|cc}
\hline \hline & Macro factor $\left(M_{t}^{(1)} \kappa\right)$ & Macro factor $\left(M_{t}^{(2)} \kappa\right)$ \\
\hline Time effect & 0.222 & 0.421 \\
Macro factor $\left(M_{t}^{(2)} \kappa\right)$ & 0.566 & \\
\hline \hline \multicolumn{3}{|c}{ b) Quarterly data } \\
\hline \hline Time effect & Macro factor $\left(M_{t}^{(1)} \kappa\right)$ & Macro factor $\left(M_{t}^{(2)} \kappa\right)$ \\
\hline Macro factor $\left(M_{t}^{(2)} \kappa\right)$ & 0.106 & 0.461 \\
\hline \hline
\end{tabular}

